\title{
Preliminary study of water and some element contents in boar spermatozoa, before, during and after freezing
}

\author{
J. L. Courtens, H. Ekwall*, M. Paquignon and L. Plöen* \\ I.N.R.A., Nouzilly, 37380 Monnaie, France; and *S.L.U, Anatomy and Histology, 75007 Uppsala, \\ Sweden
}

\begin{abstract}
Summary. Boar semen was analysed by electron microscopy coupled to image analysis and X-ray energy dispersive spectroscopy, during the usual process for freezing and thawing in field conditions. Freeze-substitution and freeze-quenching permitted recording of real or potential intracellular ice before, during, and after freezing. Heads and flagella displayed two different osmotic properties before freezing. Heads were dehydrated progressively before and during freezing, while flagella were hydrated before freezing and were only dehydrated during freezing. All parts of the thawed cells were rehydrated. Ice crystal damage was mostly present in frozen mitochondria and axonemes and the acrosomes were strongly affected by thawing. The total amounts of $\mathrm{Na}, \mathrm{Cl}, \mathrm{Ca}, \mathrm{K}, \mathrm{Mg}$, and $\mathrm{Zn}$ per cell were only elevated in frozen and thawed midpieces while the heads were permeable both to water and elements at that time.
\end{abstract}

Keywords: boar; spermatozoa; freezing; water; element concentrations; electron microscopy; image analysis; X-ray spectrophotometry

\section{Introduction}

The viability of frozen-thawed boar spermatozoa is lower than that of spermatozoa of bull, goat or ram (Paquignon et al., 1980). This could be due to considerable sensitivity of boar spermatozoa to cold shock (Polge, 1956; Mann, 1964), plasma membrane damage (Jones \& Martin, 1973; Tasseron et al., 1977), leakage of enzymes (Nath \& Patt, 1970; Pace \& Graham, 1970; Brown et al., 1971; Johnson \& Pursel, 1974; Larsson \& Einarsson, 1976), and/or modifications in the ion balance (Lovelock \& Polge, 1954; Pursel et al., 1969) followed by salting-out of proteins (Lovelock, 1953). Osmotically caused damage (Watson \& Duncan, 1988) can also occur during the treatment steps the cells have to pass through. The freezing ability of boar semen also varies greatly between sires. As for other species, the final quality of the frozen-thawed spermatozoa could be improved by the selection of animals with good freezability and/or by the modifications of some of the parameters of the techniques. Up to now, most studies have considered spermatozoa only before and after thawing, and the successive modifications of the freeze-thawing techniques have been devised with some empiricism. A better knowledge of the effects of each of the steps of the technique, including the frozen state, is needed to understand the phenomena that affect the final quality of the cells. Since defects seem to be restricted preferentially to subcellular locations such as the acrosome, flagellum and membranes, electron microscopical techniques seem appropriate for the detection of cellular damage.

The technique of cryosubstitution, to observe cells that were fixed in the frozen state (Nath, 1972; Sherman \& Liu, 1982), gives results comparable to cryosectioning (Reger et al., 1984). Using it with boar spermatozoa, Courtens \& Paquignon (1985) demonstrated the arrangement of cells inside the frozen diluent in pellets and straws.

In the present work, the amounts of water converted to ice during the usual freezing procedure have been measured using electron microscopy coupled to particle analysis on freeze-substituted 
specimens. The concentrations of some of the elements involved in the osmotic properties of the cells have been measured by X-ray energy-dispersive microspectrophotometry at several steps of the freeze-thawing technique, under conditions in which the diffusible elements are unchanged in distribution (Zierold \& Steinbrecht, 1987).

Since the modifications of biological characteristics due to the technique was the first aim, ejaculates of the same boar, one with good freezability and fertility $(75 \%$ non-return rate after insemination with frozen-thawed spermatozoa), were used to avoid individual differences. The use of electron microscopy does not easily allow quantitative work on many cells. Owing to that fact, this work can therefore be considered as preliminary to decide what step(s) of the technique is most deleterious to the cells, before any inter-individual study is developed. The techniques used were to answer the questions: (1) how much intracellular water (measured as potential ice) is present; (2) are the concentrations of common electrolytes related to the cellular water contents; and (3) are the potential osmotic properties of the cells changed during the freezing procedure?

\section{Materials and Methods}

All the cells were from ejaculates of the same boar with good fertility (see 'Introduction').

Normal freezing and thawing procedures. After mixing the ejaculated semen, the seminal plasma was discarded by centrifugation. The spermatozoa were diluted with medium containing glucose $(5.67 \mathrm{~g})$, egg yolk $(22.5 \mathrm{ml})$ and distilled water $\left(77.5 \mathrm{ml}\right.$ ) (Polge et al., 1970; Paquignon, 1985) at $30^{\circ} \mathrm{C}$. The extended spermatozoa were cooled to $15^{\circ} \mathrm{C}$ within $1 \mathrm{~h}$, and maintained at $15^{\circ} \mathrm{C}$ for 4 additional hours. The semen was extended a second time with the same volume of extender containing glycerol to obtain $2 \%$ glycerol and about $600 \times 10^{6}$ spermatozoa $/ \mathrm{ml}$. The diluted semen cooled to $5^{\circ} \mathrm{C}$ over a $1-\mathrm{h}$ period (hereafter referred to as equilibration) and frozen in $0.1 \mathrm{ml}$ pellets on solid $\mathrm{CO}_{2}$ at $-79^{\circ} \mathrm{C}$ was stored in liquid nitrogen for at least 3 days.

One volume of pellets was rapidly thawed under constant agitation in 5 volumes of $50^{\circ} \mathrm{C}$ I.N.R.A.-I.T.P. diluent (Paquignon \& Courot, 1975; Paquignon et al., 1980). The temperature of thawed specimens was $28-30^{\circ} \mathrm{C}$.

Freeze-quenching and freeze-substitution. To compare intracellular water locations and relative quantities during the preparation of freezing, two procedures were used: normal freezing and freeze-quenching.

For quenching, $0.1 \mathrm{ml}$ droplets of cell suspension were poured into melting isopentane for $5 \mathrm{~min}$ and stored in liquid nitrogen. According to Cameron et al. (1988), this procedure gives rapid cooling rates $\left(4000-5000^{\circ} \mathrm{C} / \mathrm{sec}\right.$ at the surface of the specimen). It was used for: (1) ejaculated spermatozoa; (2) centrifuged spermatozoa; (3) spermatozoa diluted for $30 \sec \left(30^{\circ} \mathrm{C}\right), 1 \mathrm{~h}$ and $4 \mathrm{~h}\left(15^{\circ} \mathrm{C}\right)$; (4) equilibrated spermatozoa $\left(4^{\circ} \mathrm{C}\right)$ immediately before freezing; and (5) thawed spermatozoa after I min in I.N.R.A.-I.T.P. medium $\left(30^{\circ} \mathrm{C}\right)$.

Regardless of the freezing procedure, all specimens were freeze-substituted and embedded in the same way. Frozen pellets or frozen-quenched droplets were fixed in $1 \%$ osmium tetroxide in acetone at $-80^{\circ} \mathrm{C}$ for 3 days and allowed to warm up to $4^{\circ} \mathrm{C}$ within $16 \mathrm{~h}$. The pellets were washed in acetone and divided in $1 \mathrm{~mm}^{3}$ blocks. After one further washing in propylene oxide, they were embedded in Epon 812. Thin sections were observed with or without uranyl and lead staining in a Philips CM 10 electron microscope coupled to image analysis.

Image analysis. The method for quantification of water, as intracellular ice, was similar in its principle to that used by Cameron et al. (1988). It was developed independently. The surfaces of sections of heads, midpieces, and principal pieces were determined with a "Quantel" particle analyser coupled to the electron microscope via a TV camera. At least 10 sections from each of the cell parts were measured. The ice and the cellular contours were visualized by thresholding the grey scale of the TV image, thus forming binary (black and white) images. The surface density (surface of ice/surface of organelle) was calculated as $\%$. Since the ice crystals were almost consistently distributed in each of the cellular parts under investigation, the surface density can also be regarded as volume density (Solari, 1973). The electron microscope magnifications were set to fill the $512 \times 512$ pixels of the video screen with the whole structure under analysis. The maximum recordable surface was 99999 pixels for the cellular part under investigation. Greater magnifications were not used to record surface densities because they did not allow area calculation of the cellular sections.

The ice content of the freeze-quenched egg yolk from the diluents, measured the same way, varied from 48 to $52 \%$ (Fig. 1), while its usual water content is $52 \%$ (Fennema et al., 1973).

The percentages were compared by means of Student's $t$ tests after modification of data as Arc.sin. $\sqrt{\%}$.

Whole-mount spermatozoa. Carbon-formvar-coated grids were floated on drops of sperm suspensions for $30 \mathrm{sec}$ at several of the steps of the freeze -thawing procedure (after centrifugation, dilution for $30 \mathrm{sec}$, dilution for $4 \mathrm{~h}$, equilibration and thawing for $1 \mathrm{~min}$ ). The excess of cells and diluent was drawn off from the grids using filter paper and the grids were rapidly air-dried. To study the frozen whole-mounted cells, grids, coated with equilibrated cells as above, 


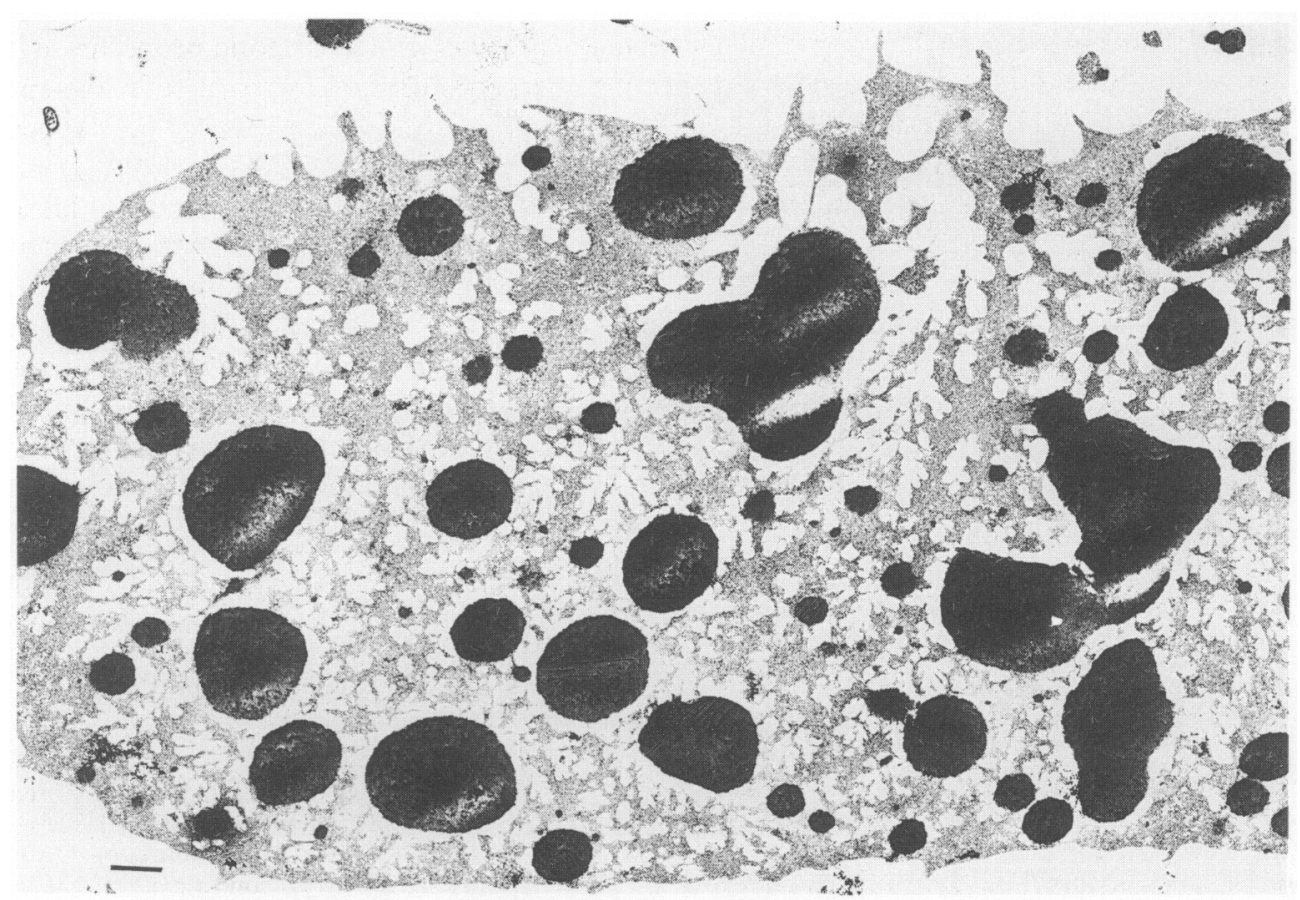

Fig. 1. Freeze-quenched, freeze-substituted particle of egg yolk from Polge's medium without glycerol $(\times 5900)$. Numerous branched ice crystals are present and in this picture they represent $51.2 \%$ of the yolk surface, which is close to the normal $(52 \%)$ hydration of fresh egg yolk.

were immediately frozen on solid $\mathrm{CO}_{2}$ for $5 \mathrm{~min}$. After incubation in liquid nitrogen for $\mathrm{I}-4 \mathrm{~h}$ for substitution of water by nitrogen, they were placed into $100 \mathrm{ml}$ liquid nitrogen in a vacuum unit. The rapid evaporation under vacuum was sufficient to cool down the nitrogen to the solid state at which lyophilization took place. After warming to room temperature under vacuum the grids were stored in a dry place before X-ray analysis.

$X$-ray microspectrophotometric analysis. Whole mount spermatozoa were analysed at $100 \mathrm{kV}$ in a TEM-STEM Philips EM-420 coupled to a Link AN-10000 energy dispersive analyser. The concentrations of 6 elements (Na, K, $\mathrm{Mg}, \mathrm{Ca}, \mathrm{Zn}$ and $\mathrm{Cl}$ ) were calculated from punctual analysis of acrosome caps (first anterior third of the head), postacrosomes (last posterior fifth of the head), necks and midpieces. Sulphur and phosphorus were also recorded to evaluate eventual drifting of the specimens during analysis, since $\mathrm{S} / \mathrm{P}$ ratios are not modified by the freezing procedure, and are organelle- and egg yolk-specific.

Five additional measurements were done from the solid medium surrounding each cell. Since the composition of egg yolk is quite constant, $150.4-\mu \mathrm{m}$ thick cryosections of egg yolk were recorded to serve as a standard for quantification. The theoretical mean values $(\mathrm{Na}, 5 \mathrm{I} ; \mathrm{Mg}, 16 ; \mathrm{P}, 590 ; \mathrm{S}, 165 ; \mathrm{Cl}, 180 ; \mathrm{K}, 138 ; \mathrm{Ca}, 140 ; \mathrm{Zn}, 4.4 \mathrm{mg} / 100 \mathrm{~g}$ hydrated yolk) were obtained from Fennema et al. (1973) and Souci et al. (1981).

The measurements were processed for the correction of backgrounds issued from the grids, grid holders and formvar films (Kendall et al., 1985) and were compared to a protein matrix containing the measured elements in known concentrations. The electron beam intensity and spot size $(20 \mathrm{~nm})$ were set not to pierce the samples during the $100 \mathrm{sec}$ record duration for each point. The comparisons of quantitative results from a preliminary trial on cryosections of nuclei and acrosomes, and acrosomes in whole-mounted cells indicated that the penetration deepness of the beam was about $0.2 \mu \mathrm{m}$. That means that the analysis of acrosomes or post-acrosomal lamina in whole-mounted specimens referred to the total thickness of these organelles, plus the underlying perinuclear substances, and a small part of the nucleus. Analysis of the midpieces related to mitochondria and part of the axonemes.

Crude semi-quantitative results were obtained as percentages of the considered elements in a protein matrix (Vs). Cells with inappropriate signal/noise ratios or with unusual S/P values (drifting) were not used in the final calculations. Calculations of the concentrations in the dry specimens were done by comparing the data in spermatozoa and egg yolk measured under the same conditions. The following formula was used: $\mathrm{Cd}=(\mathrm{Cdy} / \mathrm{Vy}) \mathrm{Vs}$ with $\mathrm{Cd}=$ calculated concentrations in dry specimen, $\mathrm{Cdy}=$ known concentrations in dry egg yolk, $\mathrm{Vy}=\%$ measured in egg yolk, Vs $=\%$ measured in the spermatozoon. 


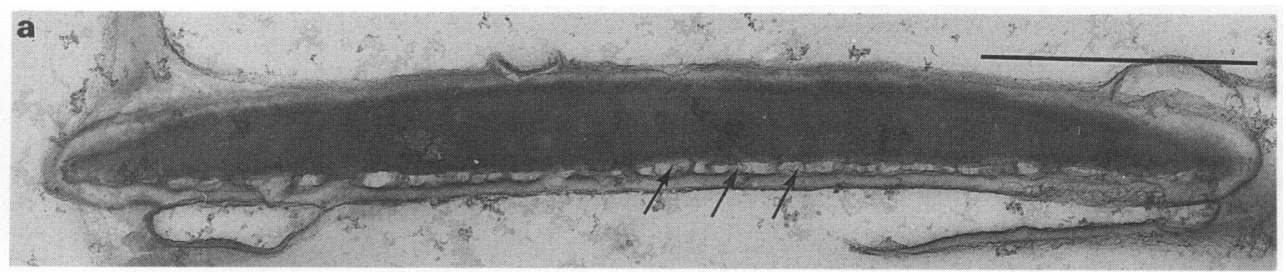

b
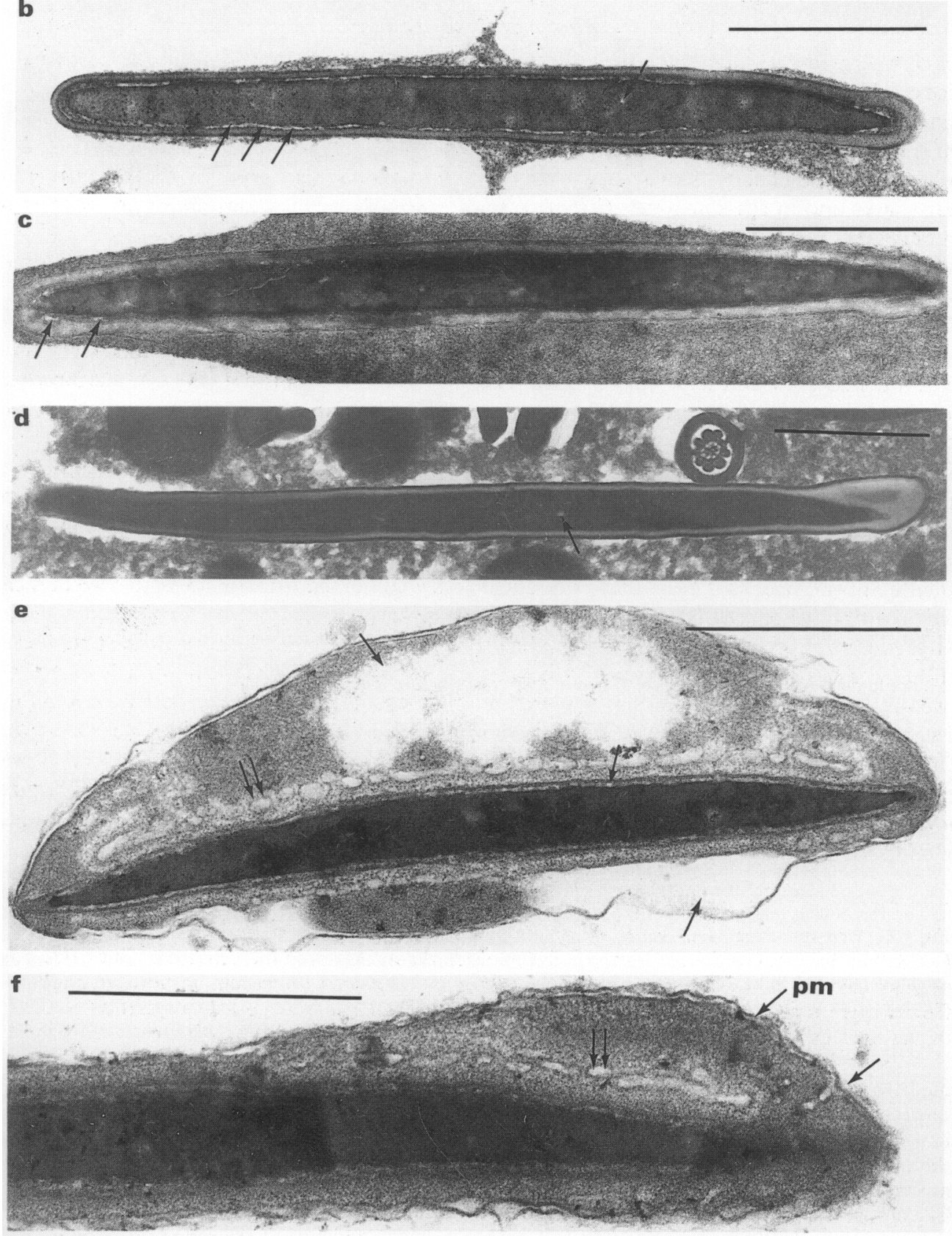
Results, expressed as mean $\mathrm{mm}$ of the element/ 1 of the hydrated cells, were calculated as follows: hydrated concentration $=$ dry concentration $/(100 /(100-\%$ ice $))$ with $\%$ ice $=$ mean surface density obtained from image analysis or arbitrarily fixed to $50 \%$ for necks.

For the technical limitations cited above, and because of limited instrumentation time, the analysis of each sample was stopped when 5 cells ( 9 measurements/cell) were suitable. The results, compared with Student's $t$ tests, can therefore only be considered as trends.

\section{Results}

Location and relative quantity of water, measured as ice crystals

Ice crystals in sperm heads. After freeze-quenching of ejaculated, diluted or equilibrated spermatozoa, ice crystals mostly occupied the perinuclear space (Figs $2 a, b, c)$. In some nuclei, the chromatin was not totally compact and some crystals were observed in nuclear 'holes' (Fig. 2b). In normally frozen specimens, the few ice crystals visually detectable were only located in these holes (Fig. 2d).

After freeze-quenching of thawed spermatozoa, ice crystals were observed both in the perinuclear spaces and in the acrosomes (Fig. 2e). About 50-60\% of the acrosomes were swollen to different degrees (the more swollen, the more hydrated they were). Vesicles were present in $30-40 \%$ of the acrosomal matrix (Fig. 2e); they could have originated from invaginations of the outer acrosomal membrane (Fig. 2f).

The surface density of ice in sperm heads was progressively lowered before freezing, and normally frozen specimens were almost devoid of ice (Fig. 3). The relative proportion of ice increased in freeze-quenched thawed cells to reach the level of ejaculated spermatozoa (Fig. 3). The large s.d. observed for these specimens resulted from variations in the hydration of the swollen acrosomes (relative ice volume up to $42 \%$ ).

Ice crystals in midpieces. After freeze-quenching, one ice crystal was located in each section of the axoneme of most midpieces, after ejaculation, centrifugation or dilution (Fig. 4). This pattern was always associated with cells embedded in the electron-dense parts of the dilution medium or in the seminal plasma. Midpieces occasionally isolated in ice, not surrounded by medium, displayed a very dense appearance, as if they were contracted. They contained little or no visible ice and the intracellular organelles were hardly distinguishable (Fig. 4a).

After equilibration, and in addition to the above observations, all mitochondria in most of the cells were filled with ice (Fig. 4b). In longitudinal sections few cells had all their mitochondria devoid of ice. This was observed also in normally frozen spermatozoa, but some cells possessed both ice-containing and ice-devoid mitochondria. Mitochondria with ice were frequently flattened (Fig. 4c).

Thawed, freeze-quenched midpieces had axonemes occupied by one ice crystal. This crystal was larger than in preceding states. It extended between the dense fibres of the axoneme and the mitochondrial helix (Fig. 4d). Mitochondria displayed various ice contents, from scarce to fully filling. Some midpieces contained both types of mitochondria.

Fig. 2. Freeze-substituted sperm heads. Bars $=1 \mu \mathrm{m}$. (a) Ejaculated, frozen-quenched ( $\times 28750$ ). Ice crystals (arrows) are present between the nucleus and the acrosome. The extracellular medium is seminal plasma. (b) Diluted for $4 \mathrm{~h}$ in Polge's medium without glycerol, frozen-quenched $(\times 27600)$. In addition to ice in the perinuclear space, one ice crystal is visible in the nucleus (arrows). (c) Equilibrated in Polge's medium with glycerol, frozen-quenched $(\times 26850)$. Little ice is present in the perinuclear space (arrows). (d) Normally frozen in Polge's medium with glycerol $(\times 21000)$. The head looks almost dehydrated. One nuclear 'hole' is depicted (arrow). (e) Thawed in I.N.R.A.-I.T.P. medium, frozen-quenched $(\times 33600)$. The acrosome is swollen. Ice crystals (single arrows) are present in the perinuclear space, between the acrosome and the plasma membrane, and inside the acrosomal matrix. Vesicles (double arrows) lie in the matrix. (f) Thawed in I.N.R.A.--I.T.P. medium, frozen-quenched $(\times 40800)$. The acrosome is not yet swollen. Intra-acrosomal vesicles (double arrow) could originate from invaginations of the outer acrosomal membrane (arrow). The plasma membrane (pm) is intact, and is not involved in vesiculization. 


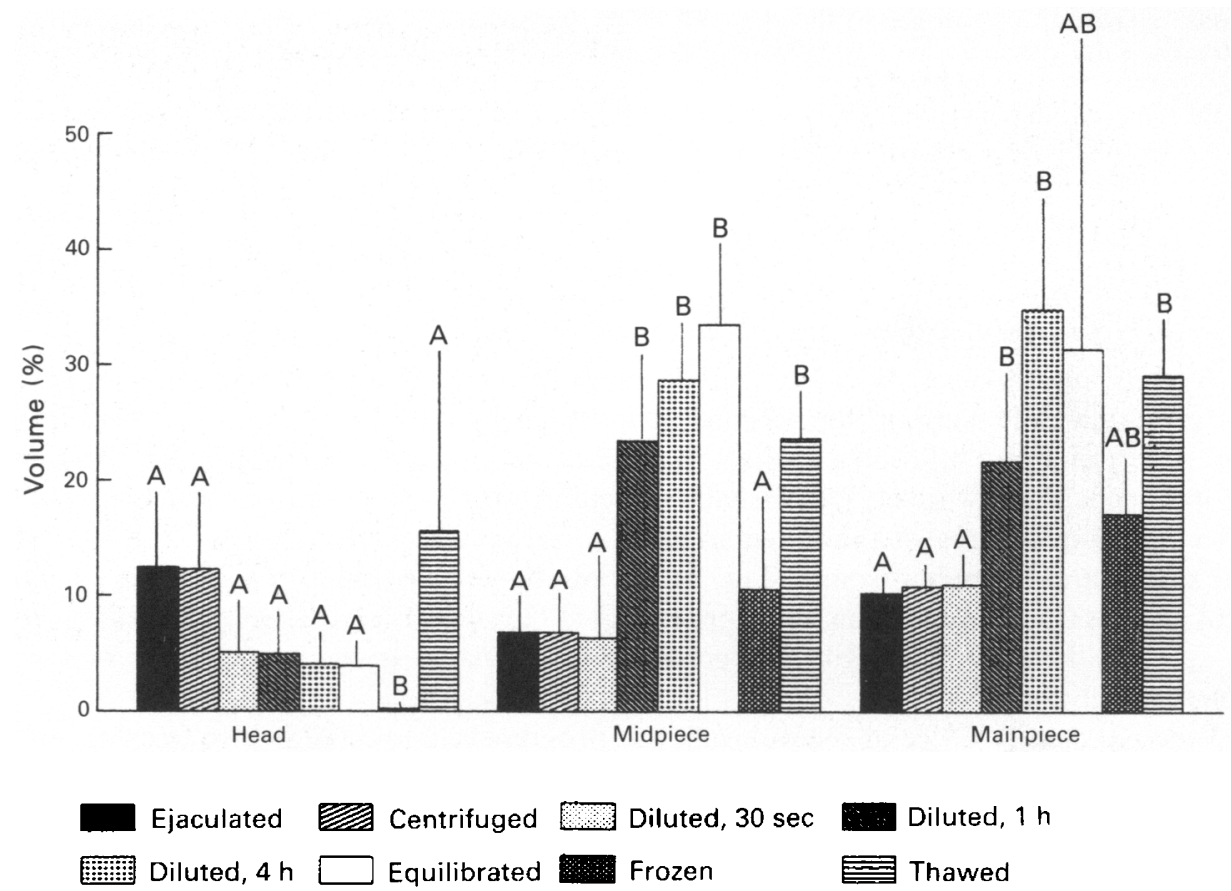

Fig. 3. Ice surface densities measured by electron microscopic granulometry. Values are means $\pm \mathrm{s} . \mathrm{d}$. for 10 spermatozoa. For one considered organelle (head, midpiece or mainpiece) bars with different letters are significantly different $(\mathrm{P}=5 \%$, Arc $\sin \sqrt{\%}$ compared by Student's $t$ tests).

Ice surface densities (Fig. 3) from ejaculation to dilution for $30 \mathrm{sec}$ were low. They increased to be about 3 times higher in specimens diluted for $1 \mathrm{~h}$ up to equilibration. The lower mean value in normally frozen spermatozoa was mostly due to the flattening of mitochondria. The higher ice surface density of freeze-quenched, thawed midpieces resulted from mixed mitochondrial populations (high and low hydration), as well as to the presence of ice under lifted plasma membranes (Fig. 3d).

Ice crystals in mainpieces. The few tails not embedded in medium were both flattened and almost dehydrated. The usual pattern for cells embedded in medium was, however, different: a large ice crystal was present in the axoneme whatever the treatment (Figs $4 \mathrm{e}, \mathrm{f}$ ). It was larger in specimens diluted for $4 \mathrm{~h}$ or equilibrated. The diameters of the main pieces were enlarged, and the axonemes were separated from the fibrous sheet by a wide space (Fig. 4f).

Fig. 4. Freeze-substituted flagella. Bars $=0 \cdot 1 \mu \mathrm{m}$. (a) Centrifuged, frozen-quenched midpiece embedded in ice $(\times 100600)$. Few internal structures are visible. The mitochondria are contracted. The midpiece looks dehydrated. The real diameter of the midpiece is only $\frac{3}{4}$ of that in Fig. 3(b). (b) Equilibrated, frozen-quenched midpiece $(\times 42300)$. The mitochondria $(M)$ and the axoneme (A) are filled with ice. (c) Normally frozen midpiece $(\times 92500)$. Ice is present in the axoneme. One ray of the radial spoke (simple arrow) is destroyed. The mitochondrion is flattened in some places (double arrow). (d) Thawed, frozen-quenched midpiece ( $\times 52500)$. A deletion in one radial spoke is visible (arrow). Ice is present between the fibres and the mitochondrial helix (double arrow), and between the mitochondrial helix and the lifted plasma membrane $(\mathrm{pm})$. (e) Normally frozen mainpiece $(\times 130000)$. Three rays of the radial spokes are destroyed by ice. (f) Equilibrated, frozen-quenched mainpiece $(\times 93600)$. The large fibres surrounding the axoneme are separated from the fibrous sheet of the flagellum (arrow). 

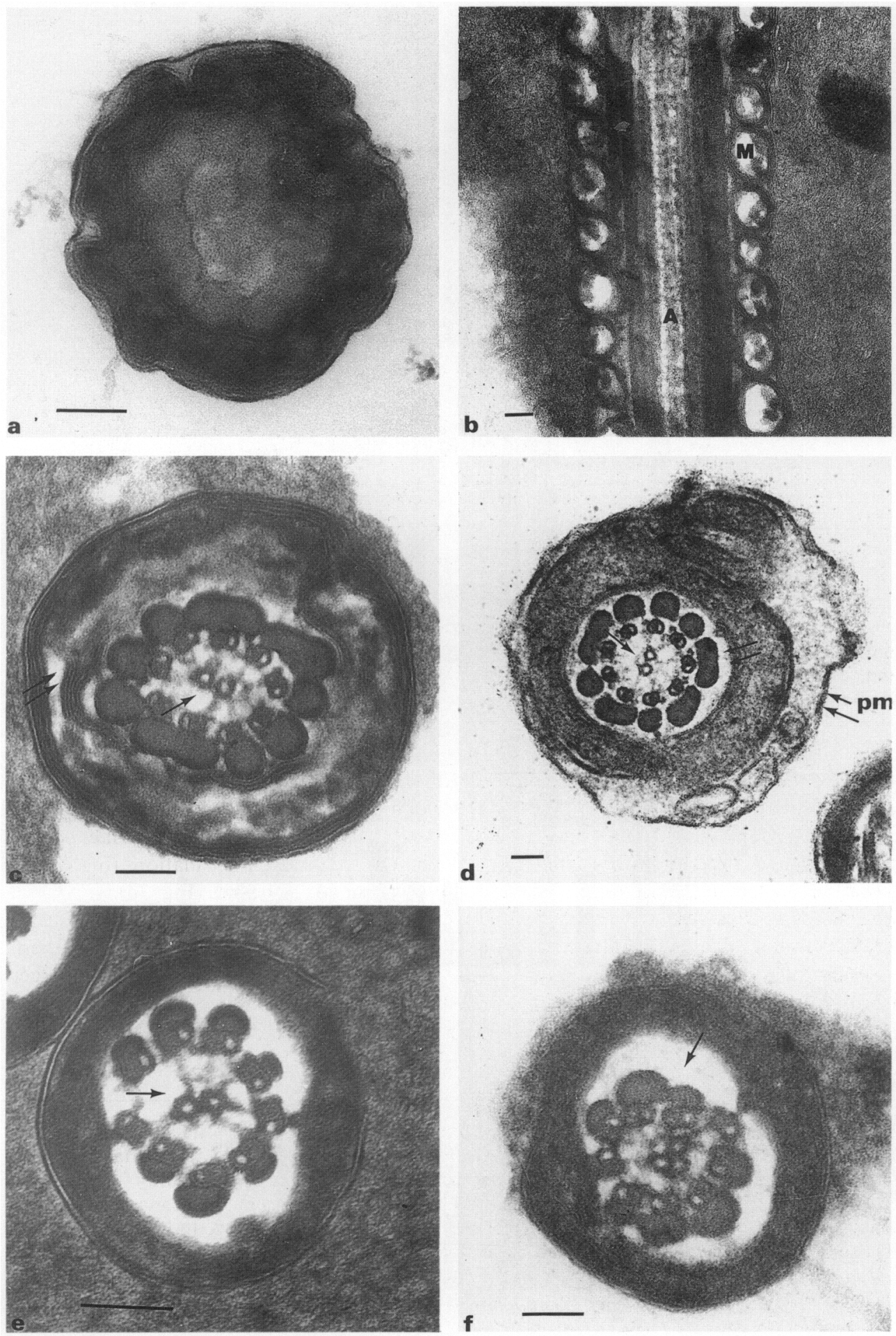


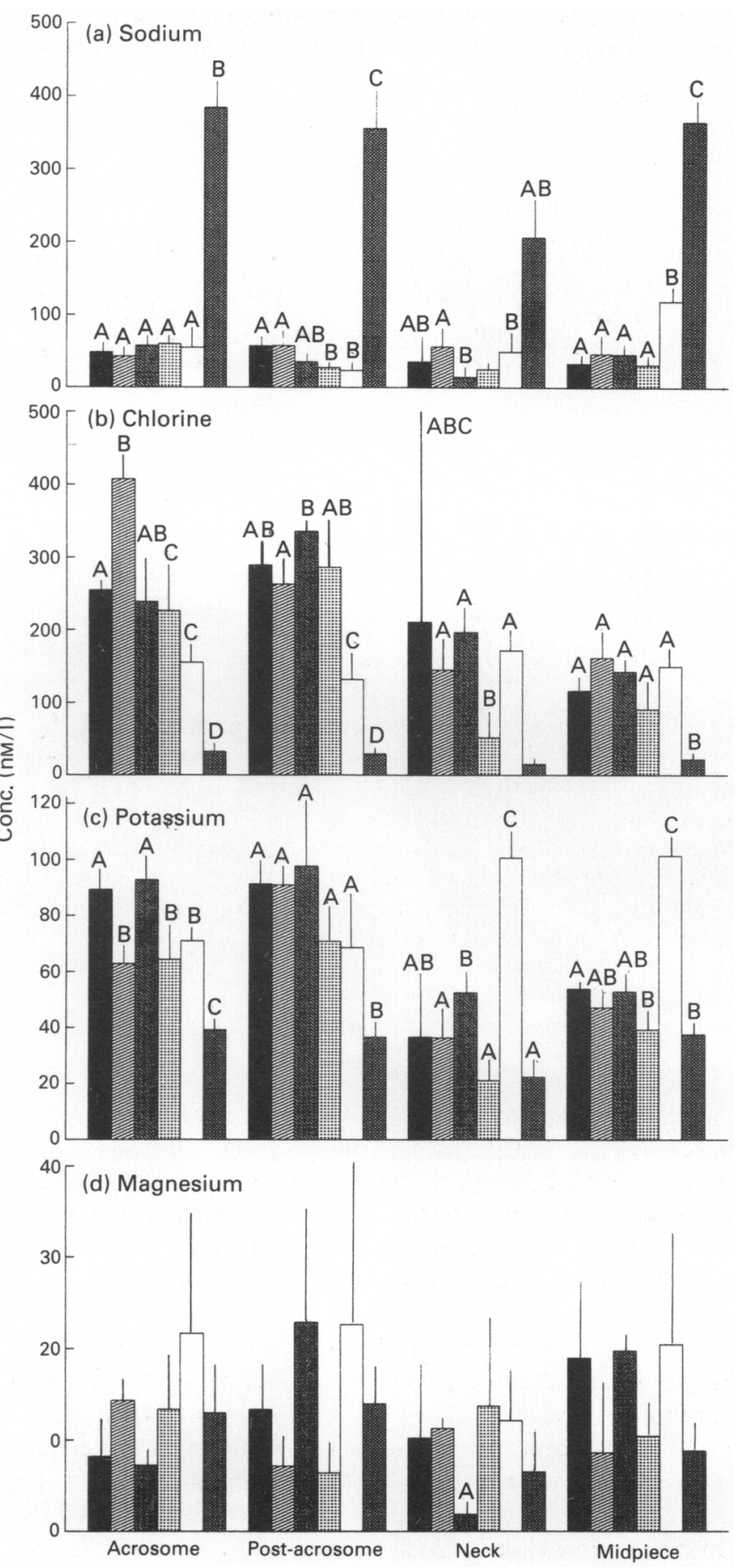




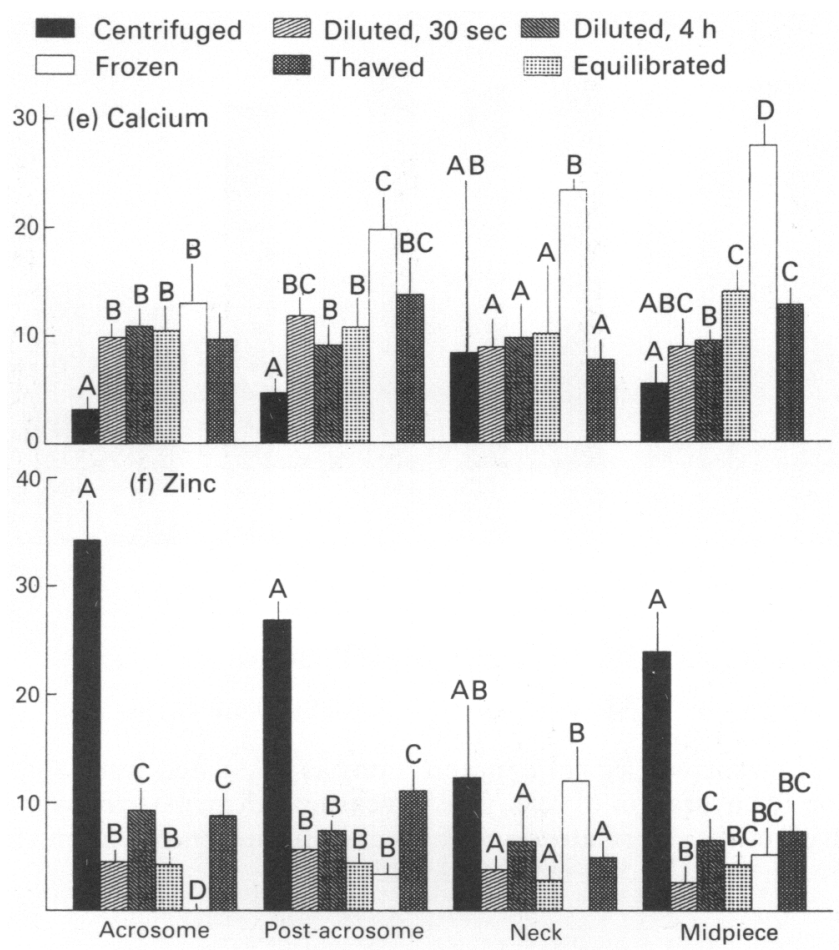

Fig. 5. Concentrations of (a) sodium, (b) chlorine, (c) potassium, (d) magnesium, (e) calcium and (f) zinc in spermatozoa. The calculation considers that the element is dissolved homogeneously in the hydrated cellular space. Values are mean \pm s.d. for 5 spermatozoa. Within one considered region (acrosome, post-acrosome, neck or midpiece) bars with different labels are significantly different $(P=5 \%$, Student's $t$ tests $)$.

\section{Cellular modifications and freezing procedure induced damages}

In sperm heads. Holes in the chromatin, not limited by membranes, are common in boar spermatozoa. They were present in all samples (Figs $2 b, c)$, and they were recorded as ice crystals. However, no difference in size and distribution between fresh, frozen, or thawed nuclei could be established.

Numerous ice crystals were located in the perinuclear space of freeze-quenched samples only (Figs $2 \mathrm{a}, \mathrm{b}, \mathrm{c}$ ). None could be recorded in normally frozen samples (Fig, 2d). Ice crystals mostly represent the degree of hydration of the organelle and are not related to any visible damage in thawed samples.

No ice was detected in acrosomes before thawing. Many thawed acrosomes displayed figures similar to those observed immediately before acrosome reaction: swelling of the acrosomal matrix and formation of membranous vesicles (Figs 2e, f). However, these alterations cannot be regarded as true acrosome reactions since the plasma membranes were never involved in vesiculization (Fig. $2 \mathrm{f}$ ).

The acrosomal and plasma membranes, as well as the nuclear envelopes were well preserved in all freeze-substituted samples (Fig. 2). No disruption or holes caused by crystals could be observed.

In midpieces. In many thawed cells, damage in the mitochondrial matrix was evident. Compressions and deformations were present in all freeze-substituted axonemes. In most normally frozen specimens, the radial spokes lying between the central and peripheral microtubules were partly destroyed (Fig. 4e). This kind of defect was not very usual in thawed samples (Fig. 4d). 


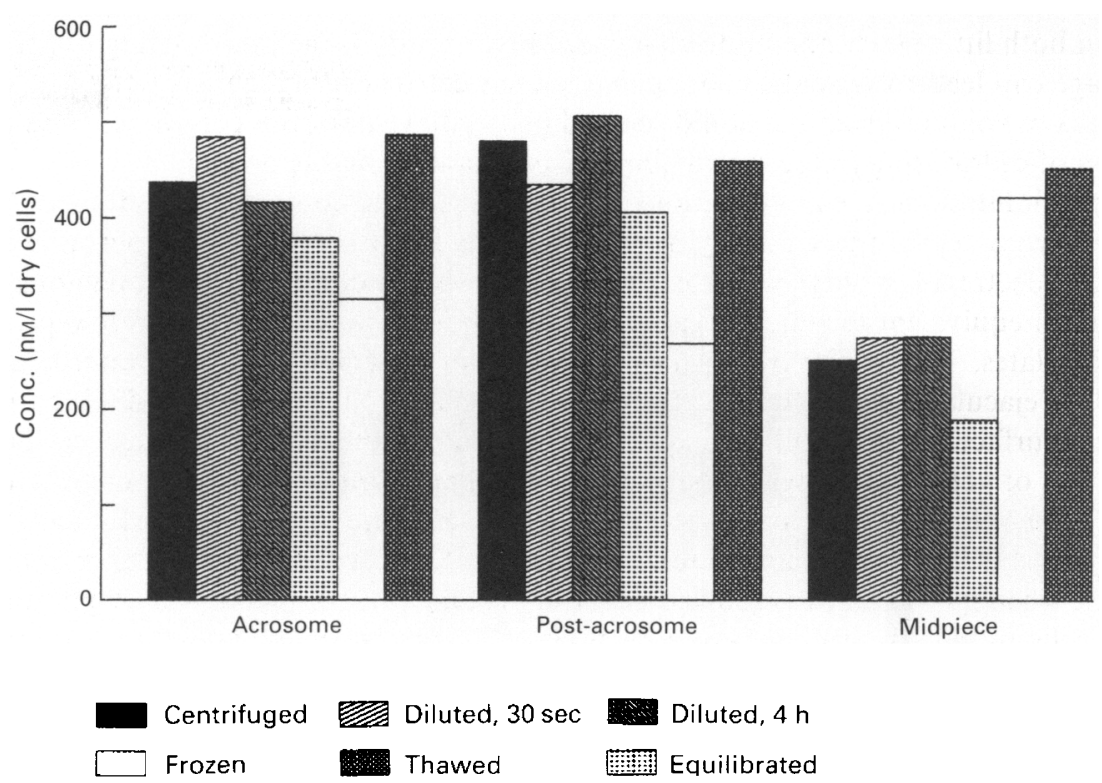

Fig. 6. Addition of measured element concentrations as calculated from X-ray spectroscopy, without correction for hydration of cells. The 6 measured elements are assumed to be homogeneously dissolved in dry spermatozoa. The total element concentration, from dilution to freezing, is lowered in heads and raised in midpieces.

\section{Quantitative X-ray microspectrophotometry}

Sodium. For each of the cellular parts measured, the mean concentrations of sodium were fairly constant before thawing. Higher values were only recorded in frozen midpieces. Sodium concentrations increased 8-10 times in thawed specimens, but the standard deviation was large due to very high concentrations in $60 \%$ of the measured cells (Fig. 5a).

Chlorine concentrations decreased progressively from dilution to thawing in acrosomes, but they were only lowered in post-acrosomes at the time of freezing and thawing. The neck and midpiece concentrations were lowered in thawed samples (Fig. 5b).

Potassium concentrations were lowered in all thawed cells as compared to preceding steps. A temporal, relative, hyperconcentration was calculated in frozen necks and midpieces (Fig. $5 \mathrm{c}$ ).

Magnesium. The high standard deviations calculated from magnesium concentrations reflect nonhomogeneous distribution of that element at the $20 \mathrm{~nm}$ resolution of the probe. The concentrations did not change significantly in the measured parts of the cell according to the treatments (Fig. 5d).

Calcium concentrations increased immediately after dilution for heads and midpieces. They were then stable for heads and continued to increase in midpieces. A transient increase was recorded in the posterior parts of the cell (post-acrosomes, necks and midpieces) during freezing (Fig. 5e).

Zinc was lowered in heads and midpieces as soon as the seminal plasma was discarded. Unlike the other elements, high concentrations could not be calculated in frozen samples (Fig. 5f).

\section{Discussion}

The amounts of ice in frozen cells or potential ice before freezing probably do not reflect the true water content in spermatozoa at the considered steps since: (1) very small crystals are probably not recorded in image analysis with the magnifications used; (2) water adsorbed to macromolecules is probably not totally converted to ice (Mazur, 1985), and this could be important in spermatozoa 
that contain both little water and quite condensed organelles; (3) the thresholding of grey levels of the TV image can lead to false deductions that some electron-lucent cellular parts are ice; (4) the modifications in volumes from the liquid to solid phases have not been considered; and (5) partial dehydration of cells during freeze quenching in isopentane probably occurs.

With these limitations, the modifications in the relative water contents, according to the steps of the freeze-thawing technique, can only be considered as trends. However, Cameron et al. (1988), using broad spectra of biological materials with known amounts of water, demonstrated the efficiency of an equivalent technique. The presently reported water contents were repeatable in 3 different ejaculates. They differ from previous evaluations predicting a total water content of at least $50 \%$ for ejaculated spermatozoa (Sherman, 1964; Drevius, 1972; Ford \& Harrison, 1983). However, ice surface densities of freeze-quenched egg yolk in the diluents are close to the reported water contents of yolk, which means that our measurements could be more accurate than indirect evaluations. The values reported here for heads of spermatozoa are consistent with the fact that nuclei, that occupy most of the head volumes, are almost dehydrated (Livoland, 1984). Other techniques are questionable when spermatozoa are considered. For instance, the comparison of weights of hydrated versus dry cells in pellets needs a careful evaluation of the water contained in the complicated extracellular spaces (Drevius, 1972). Labelling of water is probably not useful, since water adsorbed to fibrillar proteins and capillary water are almost fixed (Ling, 1988) and hardly replaceable. The present results add new information concerning the hydration of different parts of spermatozoa and demonstrate two different osmotic behaviours for heads and flagella before freezing.

The dehydration of heads and the hydration of flagella before freezing cannot be explained by the simplest osmotic hypothesis, i.e. that the intracellular concentration in osmotically active elements is kept constant by water movements across the membranes, because (1) dehydration of all parts of cells before freezing should occur in the hyperosmotic Polge's medium (420 and $750 \mathrm{mosmol} / \mathrm{kg} \mathrm{H}_{2} \mathrm{O}$ without and with glycerol); and (2) the total amount of elements/dry cell decreases in heads from centrifugation to freezing, while it increases in midpieces at the same steps (Fig. 6). Moreover, the total element concentration for heads $(400-500 \mathrm{~mm} / \mathrm{l})$ is about twice that expected for osmosis work ( $\left.290-300 \mathrm{mosmol} / \mathrm{kg} \mathrm{H}_{2} \mathrm{O}\right)$, indicating that some elements are probably bound and osmotically inactive as calculated by Drevius (1972). The observation that some ejaculated, freeze-quenched cells looked almost dehydrated when not embedded in extracellular medium, confirms that the proteins contained in media play the role of buffer against the cellular dehydration during freezing (Courtens \& Paquignon, 1985).

The oncotic properties of intracellular macromolecules can also be implied in the hydration of the spermatozoa. Heads and flagella could differ by the way and degrees their organelles are compacted. In nuclei, for instance, little additional space is available for water owing to the disulphide intramolecular bridging of the chromatin.

On the contrary, the marked and rapid dehydration of all cellular parts during freezing (Fig. 3) is consistent with osmosis theories for cells placed in the concentrated medium that surrounds extracellular ice crystals (Mazur, 1963, 1970, 1980; Clegg et al., 1982; Mansell \& Clegg, 1983). The relative higher dehydration of the flat heads during freezing could be due to a larger surface/volume ratio than that of the cylindrical flagella. The subsequent increase in intracellular solutes that only occurs in midpieces, while both water and elements are decreased in heads (Fig. 6), could refer to differences in the properties of different regions of the plasma membrane, or to damages not recordable by anatomical observations, or to the slowing down of ion escape by the numerous (and tortuous in mitochondria) membrane layers of midpieces. The intracellular element concentrations in the frozen state do not reveal any possible adverse hyperconcentration (Fig. 6). However, if all measured elements were dissolved in the little cellular water, then enormous concentrations can be calculated.

Qualitative changes in elements argue also for functional alterations of membranes. Chlorine and, to a lesser extent, potassium are lost from all cellular parts. Potassium leakage is constant from dilution to thawing. For midpieces, it could be associated with calcium penetration. Chlorine leakage is only important during freezing and after thawing. 
Increases in sodium that only occur at thawing could result from a profound alteration of specific channels since the concentration of no other element is raised to such an extent at that time.

Zinc concentrations decrease rapidly with the release of seminal plasma. This is in agreement with the rapid changes in intracellular concentrations reported by Rodriguez-Martinez et al. (1988).

The increases in calcium concentration $(\times 3)$ after a cold shock or after freeze-thawing are well documented for the spermatozoa of some species (Quinn \& White, 1966; Karagiannidis, 1976; Simpson \& White, 1986). The fast penetration in sperm heads after dilution, could be related to the abolition of a temperature-dependent, metabolic activity, while the progressive increase in midpieces could be due to an energy independent process in mitochondria (Zarca et al., 1988). Calcium is important in the initiation of the acrosome reaction (Green, 1978; Peterson et al., 1978; Jamil \& White, 1981; Bhattacharyya et al., 1986). The vesiculizations observed in many thawed acrosomes could mean that the outer membrane of the acrosome had reached a maturation degree similar to that present in capacitated cells. However, the plasma membranes were never involved, and vesiculizations were not observed before thawing, although calcium concentration was already important. This indicates that, together with calcium, the temperature-dependent metabolic activities and the modifications of the plasma membranes must all be considered (Murphy \& Yanagimachi, 1984; Tylney, 1985; Holt \& North, 1986). The storage of spermatozoa in media with high calcium contents (milk or egg yolk) could, however, be considered as one way to initiate capacitation (Courtens et al., 1984; Robertson \& Watson, 1987).

The overall modifications in $\mathrm{Na}$ and $\mathrm{Ca}$ (raised) and $\mathrm{K}$ and $\mathrm{Cl}$ (decreased) confirm previous results for whole semen (Foley \& Martin, 1968; Pursel et al., 1969; Hood et al., 1970; Ding \& Yan, 1987) and other cells (Warley, 1986). The concentrations in $\mathrm{Na}, \mathrm{K}, \mathrm{Ca}$ and $\mathrm{Mg}$ in centrifuged cells are also close to those calculated for ejaculated bull spermatozoa (Drevius, 1972).

The present results confirm that intracellular ice crystals are present in all frozen flagella (Courtens \& Paquignon, 1985) and that some damage can be repaired quite rapidly in that part of the cell. However, many of the cell modifications recorded above are irreversible and few pig spermatozoa survive thawing. Comparative studies in other species are needed to understand which, if any of the modifications described above (ice crystal damages, differential hydration/ dehydration of heads and flagella, osmotic behaviour at thawing, permeability of plasma membranes to ions) are to be considered as major, before any interindividual study is conducted or any new diluent is proposed.

\section{References}

Bhattacharyya, A., Roldan, E. \& Yanagimachi, R. (1986) Requirement of monovalent cations in the acrosome reaction of guinea pig spermatozoa. Gamete Res. 15, 285-294.

Brown, K.I., Crabo, B.G., Graham, E.F. \& Pace, M.M. (1971) Some factors affecting loss of intracellular enzymes from spermatozoa. Cryobiology 8, 220-224.

Cameron, I.L., Hunter, K.E. \& Fullerton, G.D. (1988) Quenched cooled ice crystal imprint size: a micromethod for study of macromolecular hydration. Scanning Microscopy 2, 885-898.

Clegg, J.S., Seitz, P., Seitz, W. \& Hazelwood, C.F. (1982) Cellular responses to extreme water loss: the waterreplacement hypothesis. Cryobiology 19, 306-316.

Courtens, J.L. \& Paquignon, M. (1985) Ultrastructure of fresh, frozen, and frozen-thawed spermatozoa of the boar. In Deep Freezing of Boar Semen pp. 61-87. Eds L. A. Johnson \& K. Larsson. University of Agricultural Sciences, Uppsala.
Courtens, J.L., Nunes, J.S. \& Cortell, J.M. (1984) Induction of the acrosome reaction in the spermatozoa of the goat by secretions of the male accessory glands and milk. Gamete Res. 9, 287-302.

Ding, J.C. \& Yan, Z.S. (1987) Changes in cation concentrations in boar spermatozoa during incubation and after cold shock and rapid freezing. J. Jangsu agric. Coll. 7, 9-12.

Drevius, L.O. (1972) Water contents, specific gravity and concentrations of electrolytes in bull spermatozoa. $J$. Reprod. Fert. 28, 15-28.

Fennema, O.W., Powrie, W.D. \& Marth, E.H. (1973) Low Temperature Preservation of Foods and Living Matter. Marcel Dekker, Inc., New York.

Foley, C.W. \& Martin, T.G. (1968) Cation concentration changes in boar spermatozoa. J. Anim. Sci. 27, 1192, abstr.

Ford, W.C.L. \& Harrison, A. (1983) D- $\left[1-{ }^{14}\right.$ C $]$ Mannitol and $\left[\mathrm{U}-{ }^{14} \mathrm{C}\right]$ sucrose as extracellular space markers for 
human spermatozoa and the uptake of 2-deoxyglucose. J. Reprod. Fert. 69, 479487.

Green, D.P.L. (1978) The induction of acrosomal reaction in Guinea-pig sperm by the divalent metal cation ionophore A23187. J. Cell Sci. 32, 37-151.

Holt, W.V. \& North, R.D. (1986) Thermotropic phase transition in the plasma membrane of ram spermatozoa. J. Reprod. Fert. 78, 447-457.

Hood, R.D., Foley, C.W. \& Martin, T.G. (1970) Effects of cold shock, dilution, glycerol and dimethyl sulfoxide on cation concentrations in porcine spermatozoa. J. Anim. Sci. 30, 91-94.

Jamil, K. \& White, I.G. (1981) Induction of acrosomal reaction in sperm with ionophore A23187 and calcium. Archs Androl. 7, 283-292.

Johnson, L.A. \& Pursel, V.G. (1974) Effect of cold shock and freezing on acrosomal proteinase of porcine spermatozoa. Cryobiology 11, 558, abstr.

Jones, R.C. \& Martin, I.C.A. (1973) The effects of dilution, egg yolk and cooling to $5^{\circ} \mathrm{C}$ on the ultrastructure of ram spermatozoa. J. Reprod. Fert. 35, 311-320.

Karagiannidis, A. (1976) The distribution of calcium in bovine spermatozoa and seminal plasma in relation to cold shock. J. Reprod. Fert. 46, 83-90.

Kendall, M.D., Warley, A. \& Morris, I.W. (1985) Differences in apparent elemental composition of tissues and cells using a fully quantitative X-ray microanalysis. J. Microscopy 138, 35-42.

Larsson, K. \& Einarsson, S. (1976) Fertility of deep frozen boar spermatozoa. Influence of thawing diluents and of boars. Acta vet. scand. 17, 43-62.

Ling, G.N. (1988) A physical theory of the living state: application to water and solute distribution. Scanning Microscopy 2, 899-913.

Livoland, F. (1984) Cholesteric organization of DNA in the stallion sperm head. Tissue \& Cell 16, 535-555.

Lovelock, J.E. (1953) The mechanism of the protective action of glycerol against haemolysis by freezing and thawing. Biochim. Biophys. Acta 11, 28-36.

Lovelock, J.E. \& Polge, C. (1954) The immobilization of spermatozoa by freezing and thawing and the protective action of glycerol. Biochem. J. 58, 618-622.

Mann, T. (1964) The Biochemistry of Semen and of the Male Reproductive Tract. Methuen, London.

Mansell, J.L. \& Clegg, J.S. (1983) Cellular and molecular consequences of reduced cell water content. Cryobiology 20, 591-612.

Mazur, P. (1963) Kinetics of water loss at subzero temperatures and the likelihood of intracellular freezing. J. gen. Physiol. 47, 347-369.

Mazur, P. (1970) Cryobiology: the freezing of biological systems. Science, $N Y 168,939-949$.

Mazur, P. (1980) Limits of life at low temperature and at reduced water contents and water activities. Origins Life 10, 137-159.

Mazur, P. (1985) Basic concepts in freezing cells. In Deep Freezing of Boar Semen, pp. 91-111. Eds L. A. Johnson \& K. Larsson. University of Agricultural Sciences, Uppsala.

Murphy, S.J. \& Yanagimachi, R. (1984) The pH dependence of motility and the acrosome reaction of guinea pig spermatozoa. Gamete Res. 10, 1-8.

Nath, J. (1972) Correlative biochemical and ultrastructural studies on the mechanism of freezing damage to ram sperm. Cryobiology 9, 240-246.
Nath, J. \& Patt, J. (1970) Biochemical changes associated with freezing in ram semen. Cryobiology 6, 240-246.

Pace, M.M. \& Graham, E.F. (1970) The release of glutamic oxaloacetic transaminase from bovine spermatozoa as a test method of assessing semen quality and fertility. Biol. Reprod. 3, 140-146.

Paquignon, M. (1985) Freezing and thawing extenders for boar spermatozoa. In Deep Freezing of Boar Semen, pp. 125-145. Eds L. A. Johnson \& K. Larsson. University of Agricultural Sciences, Uppsala.

Paquignon, M. \& Courot, M. (1975) Survie des spermatozoïdes de verrat après décongélation. Effet du rythme de collectes, de la concentration et du taux de glycérol. Annls Biol. anim. Biochim. Biophys. 15, 517-523.

Paquignon, M., Bussière, J., Bariteau, F. \& Courot, M. (1980) Effectiveness of frozen boar semen under practical conditions of artificial insemination. Theriogenology 14, 217-226.

Peterson, R.M., Russel, L., Bundman, D. \& Freund, M. (1978) Effect of ionophore induced calcium uptake and dibutyrylcyclic AMP on the acrosome membrane of boar spermatozoa. Fedn Proc. Fedn Am. Socs. exp. Biol. 37, 380, abstr.

Polge, C. (1956) Artificial insemination in pigs. Vet. Rec. 68, 62-76.

Polge, C., Salamon, S. \& Wilmut, I. (1970) Fertilizing capacity of frozen boar semen following surgical insemination. Vet. Rec. 87, 424-428.

Pursel, V.G., Johnson, L.A. \& Gerritz, R.J. (1969) Effect of cold shock and freezing on cations of boar spermatozoa. J. Anim. Sci. 29, 196, abstr.

Quinn, P.J. \& White, I.G. (1966) The effect of cold shock and deep-freezing on the concentration of major cations in spermatozoa. J. Reprod. Fert. 12, 263-270.

Reger, J.F., Escaig, F., Pochon-Masson, J. \& Fitzgerald, M.R.C. (1984) Observations on crab, carcinus maenas spermatozoa following rapid freeze and conventional fixation technique. J. Ultrastruct. Res. 89, 12-22.

Robertson, L. \& Watson, P.F. (1987) The effect of egg yolk on the control of intracellular calcium in ram spermatozoa cooled and stored at $5^{\circ} \mathrm{C}$. Anim. Reprod. Sci. 15, 177-187.

Rodriguez-Martinez, H., Kvist, U., Courtens, J.L. \& Plöen, L. (1988) Post-testicular nuclear changes in boar spermatozoa. Proc. 11th. Int. Congr. Anim. Reprod. \& A.I., Dublin, 3, Art. no. 291

Sherman, J.K. (1964) Low temperature research on spermatozoa and eggs. Cryobiology 1, 103-129.

Sherman, J.K. \& Liu, K.C. (1982) Ultrastructure before freezing, while frozen, and after thawing in assessing cryoinjury of mouse epididymal spermatozoa. Cryobiology 19, 503-510.

Simpson, A.M. \& White, I.G. (1986) Effect of cold shock and cooling rate on calcium uptake of ram spermatozoa. Anim. Reprod. Sci. 12, 131-143.

Solari, A. (1973) Etude quantitative d'organes et de tissus. I. Methodes d'estimation des volumes. Annls Biol. anim. Biochim. Biophys. 13, 247-265.

Souci, S.W., Fachmann, W. \& Kraut, H. (eds) (1981) In Food Composition and Nutrition Tables, 1981-1982, 2nd edn, pp. 136-137. Wissenschaftliche Verlags Gesellschaft M.B.H., Stutgart.

Tasseron, F., Amir, D. \& Schindler, H. (1977) Acrosome 
damage of ram spermatozoa during dilution, cooling and freezing. J. Reprod. Fert. 51, 461-462.

Tylney, L.G. (1985) The acrosome reaction. In Biology of Fertilization 2, 157-210. Eds C. B. Metz \& A. Monroy. Academic Press, Orlando.

Warley, A. (1986) Elemental concentration in isolated thymocytes prepared for cryofixation in the presence of different media. J. Microsc. 144, 183-191.

Watson, P.F. \& Duncan, A.E. (1988) Effect of salt concentration and unfrozen water fraction on the viability of slowly frozen ram spermatozoa. Cryobiology $\mathbf{2 5}$, 131-142.
Zarca, A., Rubinstein, S. \& Breibart, H. (1988) Transport mechanism for calcium and phosphate in ram spermatozoa. Biochim. Biophys, Acta 944, $351-358$.

Zierold, K. \& Steinbrecht, R.A. (1987) Cryofixation of diffusible elements in cells and tissues for electron probe analysis. In Cryotechniques in Biological Electron Microscopy, pp. 272-282. Eds R. A. Steinbrecht \& Zierold. K. Springer-Verlag, Berlin.

Received 27 February 1989 